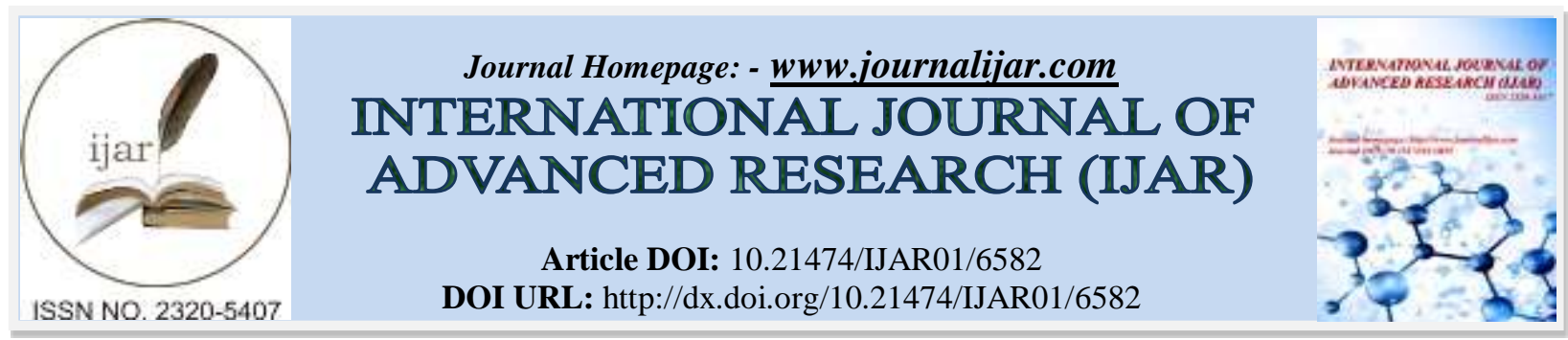

RESEARCH ARTICLE

\title{
DELAYED PRESENTATION OF DUODENAL PERFORATION FOLLOWING BLUNT ABDOMINAL TRAUMA.
}

\section{Adel Gaafar Elbagir MBChB FRCS, Yaqeen Yahya Muazen MBBS and Mohammad Jamal Sharroufna MBBS. \\ Department of Surgery, King Fahd Hospital of The University, Imam Abdulrahman Bin Faisal University, Alkhobar, Kingdom of Saudi Arabia.}

\section{Manuscript Info}

\section{Manuscript History}

Received: 19 December 2017

Final Accepted: 21 January 2018

Published: February 2018

Key words:-

Duodenal Rupture, Blunt Abdominal

Trauma, Delayed presentation,

Diagnostic modality.

\begin{abstract}
We present a case of a 19-year-old male who sustained multiple injuries following high speed motor vehicle accident. Patient had a delayed presentation of peritonitis at the third day of admission. CT scan was done after the development of peritonitis and showed retroperitoneal free air and injury to the second part of duodenum, that was not found in CT scan done on admission. Patient underwent laparotomy with primary duodenal repair at the third day of presentation. He had uneventful recovery and was discharged 25 days later. Duodenal rupture is a rare but serious complication of blunt abdominal trauma that is commonly missed due to its delayed presentation.
\end{abstract}

Copy Right, IJAR, 2018,. All rights reserved.

\section{Introduction:-}

Blunt abdominal trauma commonly develops following motor vehicle accidents. Of blunt abdominal organ injuries, duodenal injuries are relatively rare, and its diagnosis and management continue to be challenging (1). Blunt duodenal injuries are both less common and more difficult to diagnose than penetrating injuries, it commonly occurs following crushing of the duodenum between spine and steering wheel in motor vehicle accidents or some other anterior abdominal forces (2). While the most commonly affected retroperitoneal organ in blunt abdominal trauma is the pancreas, representing $28 \%$ of all retroperitoneal organs, duodenal injuries represent only $0.2 \%$ to $3.7 \%$. Furthermore, duodenal injuries represent only $1.5 \%$ of blunt small bowel injuries being the least commonly affected part of small bowel compared to $46.2 \%$ of the ilium (3). Although early diagnosis of duodenal injuries is critical and associated with lower rates of morbidity and mortality, patients with this type of injury commonly present with subtle clinical findings delaying the diagnosis and management $(1,4)$.

\section{Case Report:-}

We report a case of a 19-year-old Saudi male, medically free, who was brought early morning by ambulance to the emergency department of our hospital as a case of polytrauma following motor vehicle accident. He was the driver being ejected from his car after rolled over. Patient sustained torso trauma resulting in left lung contusions, right acetabulum fracture and right open patellar fracture. On admission, patient was fully conscious with GCS 15/15 vitally stable, complaining of chest pain, pain in multiple areas of right lower limb and generalized abdominal pain. ATLS protocol was applied. During secondary survey, there was lower abdominal tenderness but no guarding or rigidity. Abdominal CT scan was done which showed no contrast extravasation, free fluid or gas within the abdomen or pelvic cavity (Figures 1 and 2). Initial blood analysis showed leukocytosis $\left(15 \times 10^{9} / \mathrm{L}\right)$ and normal hemoglobin 
(15 g/dl), liver function test, amylase $(53 \mathrm{U} / \mathrm{L})$ and lipase $(272 \mathrm{U} / \mathrm{L})$. At the second day of admission, patient condition was stable but still there is lower abdominal tenderness, with no rigidity. His repeat blood analysis was within normal limits except for leukocytosis $\left(16.6\right.$ X $\left.10^{9} / \mathrm{L}\right)$ and slightly raised CRP (19.7 mg/dl), lactate level was normal. Abdominal and pelvic ultrasound done in the second day of admission showed mild to moderate hepatorenal and pelvic fluid collection. At the the third day of presentation, patient started to develop sever generalized abdominal pain associated with generalized abdominal tenderness, rigidity and reduced bowel sounds, but was vitally stable. Repeat blood analysis showed white blood cell count of ( 8.9 X $\left.10^{9} / \mathrm{L}\right)$, Hemoglobin at (10.8 g/dl) and increased level of lipase to $(602 \mathrm{U} / \mathrm{L})$. CT scan with contrast was repeated at the third day of presentation and showed large perforation at the second part of the duodenum, free fluid and air (Figures 3 and 4). Patient underwent laparotomy, duodenal debridement and repair followed by Roux-en-Y gastrojejunostomy. Patient recovered uneventfully and discharged from general surgery service 25 days later.

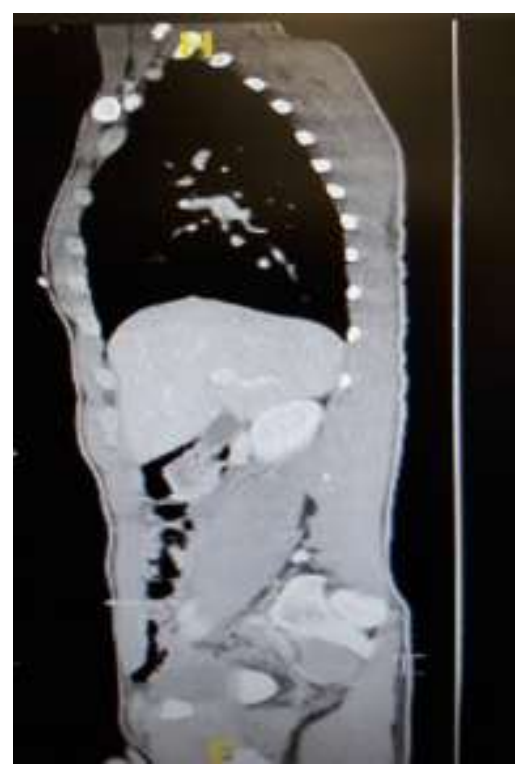

Figure 1:- Sagittal CT image showing no free fluid or air

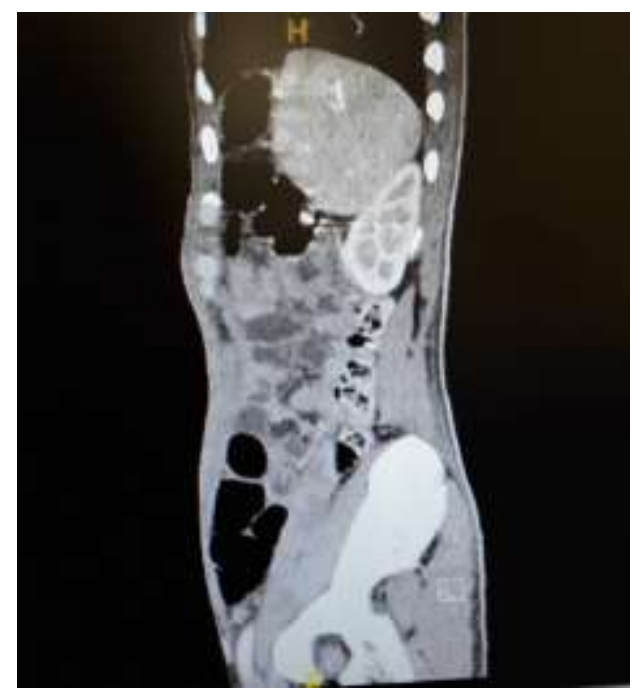

Figure 3:- Sagittal CT image showing free fluid and air

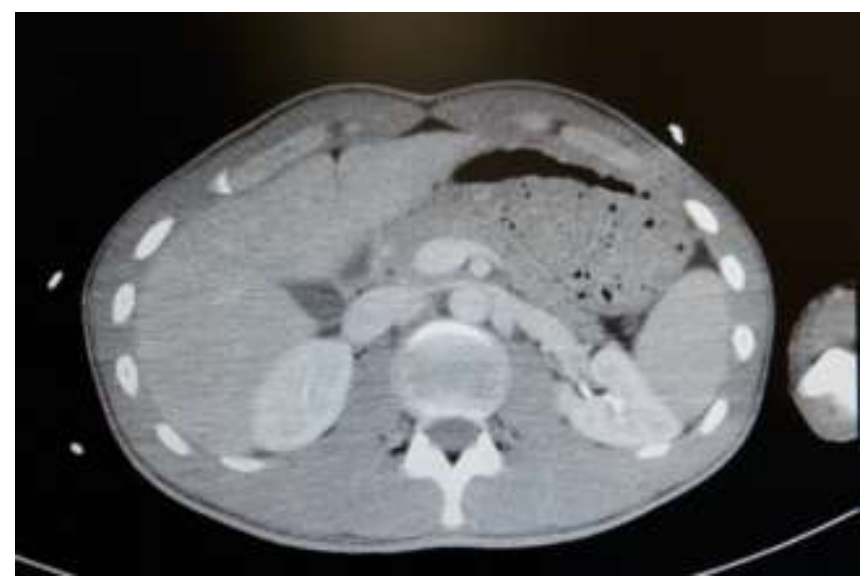

Figure 2:- Axial CT image Showing no free fluid or air

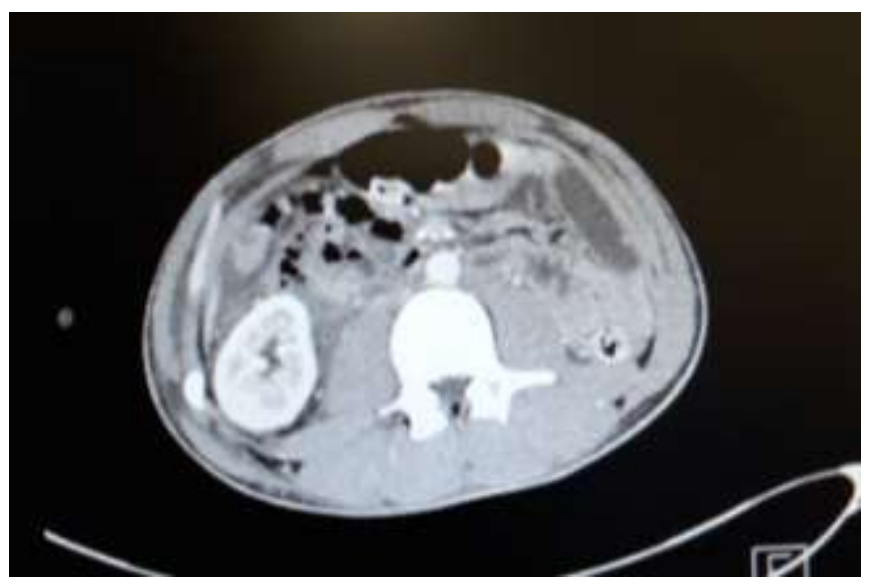

Figure 2:- Axial CT image Showing free fluid and air 


\section{Discussion:-}

Duodenal perforation may result from a direct blow to the abdomen (especially epigastric area) by the steering wheel in motor vehicle accidents (2), leading to a shearing force resulting of simultaneous closure of the pylorus and the forth part of the duodenum resulting in closed loop obstruction $(5,6)$.

Early diagnosis of duodenal injury is critical, as delayed diagnosis more than 24 hours associate with increase in mortality from $5 \%$ to $65 \%$ (7). The delayed nature of duodenal injury presentation is mainly attributed to the dull nature symptoms, and physical examination may not be helpful in early diagnosis of duodenal perforation. The rare nature of this type of injury may also result in delayed suspicion and diagnosis. Patients may present with tachycardia, epigastric or right upper quadrant tenderness and vomiting which are common but rather not specific findings $(1,5)$. Peritoneal signs usually occur later in the course of injury resulting from extravasation of duodenal contents into the peritoneal cavity (1).

Abdominal radiographs may be helpful in only small number of patients when gas bubbles are present in the retroperitoneum adjacent to the right psoas muscle, around the right kidney or anterior to the upper lumbar spine, and therefore, it is not routinely indicated in evaluating patients with mid-abdominal injuries $(1,3)$. An upper gastrointestinal series using water-soluble contrast material provides positive results in $50 \%$ of the patients. CT scan is a highly sensitive diagnostic modality, it may show peritoneal air, blood or contrast extravasation. In equivocal radiographic findings with high index of suspicion, exploratory laparotomy remains the ultimate diagnostic test (3). Duodenal injuries are classified according to the Organ Injury Scoring Scale of the American Association for the Surgery of Trauma (AAST) into five grades (Table 1) (8). The choice of management of duodenal injuries depends on several factors, including the severity of injury, involvement of adjacent organs and the general condition of the patient (1). Most duodenal injuries can be managed successfully by simple repair. More complicated injuries require more sophisticated techniques (3).

\begin{tabular}{|l|l|l|}
\hline Grade & Type of injury & Injury Description \\
\hline I & $\begin{array}{l}\text { Hematoma } \\
\text { Laceration }\end{array}$ & $\begin{array}{l}\text { Involving single portion of duodenum } \\
\text { Partial thickness, no perforation }\end{array}$ \\
\hline II & $\begin{array}{l}\text { Hematoma } \\
\text { Laceration }\end{array}$ & $\begin{array}{l}\text { Involving more than one portion } \\
\text { Disruption }<50 \% \text { of circumference }\end{array}$ \\
\hline III & Laceration & $\begin{array}{l}\text { Disruption of 50 }-75 \% \text { of circumference of D2 } \\
\text { Disruption of 500 }-100 \% \text { of D1,D3, D4 }\end{array}$ \\
\hline IV & Laceration & $\begin{array}{l}\text { Disruption of } \\
\text { Involving ampulla of distal CBD }\end{array}$ \\
\hline V & Laceration & $\begin{array}{l}\text { Massive disruption of duodenalpancreatic complex } \\
\text { Devascularization of duodenum }\end{array}$ \\
\hline
\end{tabular}

Table 1:- Deodenum Organ Injury Scale According to AAST

(American Association for the Surgery of Trauma)

\section{Conclusion:-}

Duodenal perforation is a serious condition. A high index of suspicion for occult duodenal injury should be exercised in all cases of blunt abdominal injury.

Many factors may play a role in the delayed presentation of traumatic duodenal perforation; including its anatomical location as a retroperitoneal organ and its low incidence makes it less likely to be identified unless a high degree of suspicion is maintained. Symptoms might not develop until peritonitis is developed. Early identification and treatment of such injuries is critical. Usually multiple CT scans, contrast studies or more complex imaging techniques are required for the confirmation of the diagnosis. 


\section{References:-}

1. J-F, F., R-J, C. \& B-C, L. 1999, "Surgical Treatment and Outcome after Delayed Diagnosis of Blunt Duodenal Injury", European Journal of Surgery, vol. 165, no. 2, pp. 133-139.

2. Degiannis, E. \& Boffard, K. 2000, "Duodenal injuries", British Journal of Surgery, vol. 87, no. 11, pp. 14731479.

3. Ahmad.R,Shafique.M,Akram.Z,Qureshi.U,Khan.J,2016,Isolated duodenal injuries after blunt Abdominal Trauma,pages 400-403.

4. Mcwhirter, D. 2011, "Duodenal rupture following trauma in a child", Scottish Medical Journal, vol. 56, no. 2, pp. 1-2.

5. Torba.M,Gjata.A,Buci.S,Troci.A,Subashi.K,2013,Delayed presentation of blunt duodenal injuries in children, Case report and review of literature, page 122-124.

6. Mcwhirter, D. 2011, "Duodenal rupture following trauma in a child", Scottish Medical Journal, vol. 56, no. 2, pp. 1-2.

7. Toxopeus MD, Lucas CE, Krabbenhoft KL. Roentgen graphic diagno- sis on blunt retroperitoneal duodenal rupture. Am J Roent 1972;115: 281-8

8. Moore EE, Cogbill TH, Malagoni MA, et al. Organ injury scaling, II: pancreas, duodenum, small bowel, colon and rectum. J Trauma 1990;30:1427 - 9 